\title{
PERSPECTIVAS METACOGNITIVAS E METALINGUÍSTICAS PARA O ENSINO DE LEITURA E ESCRITA EM LÍNGUA MATERNA
}

\author{
METACOGNITIVE AND METALINGUISTIC PERSPECTIVES TO \\ THE TEACHING OF READING AND WRITING
}

\author{
Patricia Ferreira Botelho (UFRN) ${ }^{1}$ \\ Fabiana Esteves Neves (UFF) ${ }^{2}$
}

\begin{abstract}
RESUMO
Com o propósito de contribuir no debate sobre o ensino de leitura e escrita em língua materna no Brasil, reunimos alguns estudos, de base cognitivo-ecológica e metacognitiva, na forma de uma proposta geral de abordagem desses conteúdos, vistos aqui como habilidades processuais. Neste sentido, nosso trabalho visa refletir sobre as dificuldades e as habilidades de leitura e escrita dos alunos para, então, propor alternativas de desenvolvimento dessas atividades para professores e estudantes. Primeiramente, apresentamos alguns pressupostos em cognição, metacognição e gerenciamento metalinguístico que fundamentam a abordagem da leitura e da escrita. Em seguida, problematizamos as concepções sobre ler e escrever ainda vigentes na escola e oferecemos alternativas que consideram leitura e escrita como processos. Por fim, destacamos como componentes centrais da proposta as estratégias metacognitivas e metalinguísticas, caminho de orientação sobre as formas como as pessoas podem pensar acerca das atividades que realizam ao ler e escrever.
\end{abstract}

PALAVRAS-CHAVE: Leitura; Escrita; Metacognição; Ensino.

\begin{abstract}
Our article aims at contributing to the discussion about the teaching of reading and writing in Brazil. For this purpose, we review the literature about reading and writing on the light of an ecological cognition perspective and metacognition and consider reading and writing as composing processes. In this sense, our paper reflects on students' reading and writing difficulties and skills in order to offer alternative ways of developing reading and writing tasks for teachers to apply to their students. First, we present concepts of cognition, metacognition and metalinguistic knowledge. Then, we discuss the concepts of reading and writing that have been in use at schools, and present alternatives which consider reading and writing as composing processes. Finally, we highlight, as central features of this proposal, metacognitive and metalinguistic strategies as a way of making people aware of the tasks they perform while reading and/or writing.
\end{abstract}

KEYWORDS: Reading; Writing; Metacognition; Teaching.

\section{INTRODUÇÃO}

Conteúdos centrais do ensino de língua materna no Brasil, a leitura e a escrita continuam no cerne dos debates mais polêmicos sobre políticas educacionais no país e na mira de avaliações

\footnotetext{
${ }^{1}$ Professora adjunta do Departamento de Letras da Universidade Federal do Rio Grande do Norte (DELET/UFRN). Doutora em Letras Vernáculas pela Universidade Federal do Rio de Janeiro (UFRJ). patriciabotelho@cchla.ufrn.br

${ }^{2}$ Professora adjunta do Departamento de Letras Clássicas e Vernáculas da Universidade Federal Fluminense (GLC/UFF). Doutora em Letras Vernáculas pela Universidade Federal do Rio de Janeiro (UFRJ). fabianaen@id.uff.br
} 
nacionais e internacionais, que atrelam o grau de desenvolvimento intelectual de um povo à sua compreensão do que lê e à sua capacidade de expressão. Além disso, mudanças nas diretrizes e orientações para o ensino ocorridas nos últimos anos, ainda em consolidação, impactam a produção de materiais didáticos e suscitam discussões sobre os pressupostos que as sustentam. Diante desse cenário, trazemos uma síntese de nossas propostas para leitura e escrita fundamentadas em abordagens teóricas de base cognitivo-ecológica e metacognitiva. Pensando o ensino, o principal foco dessas abordagens é a pessoa do estudante, que realiza ações (meta)cognitivas ao ler e escrever.

Nossa discussão nasce da escolha por olhar a aprendizagem em leitura e escrita como processo e das motivações para apontar caminhos colaborativos para o que há em termos de ensino dessas habilidades. Como as noções de leitura e de escrita propostas no meio escolar não têm correspondido às maneiras pelas quais as pessoas cognizam ao desenvolver essas atividades (BOTELHO, 2010; 2015; VARGAS, 2012; 2017; ALMEIDA, 2017), elegemos esse diagnóstico como ponto de partida a fim de propor formas de repensar tanto a leitura quanto a escrita como ações cognitivas plenas. Neste sentido, nosso trabalho visa refletir sobre as dificuldades e as habilidades de leitura e escrita dos alunos, assim como sobre pressupostos teóricos que vêm fundamentando as práticas de ensino, para, então, sugerir um aparato teórico-descritivo com foco nas estratégias metacognitivas e metalinguísticas, como um caminho interessante de reorganização dessas atividades para professores e estudantes.

\title{
1 Leitura e escrita - alguns pressupostos em cognição e em metacognição
}

A linguagem humana deve ser compreendida sob a premissa de um conjunto de noções, de convenções e de práticas voltado para a necessidade de construir significados, enunciar conceitos, comunicar, estabelecer experiências com o mundo. Vale ressaltar algumas contribuições de Gerhardt acerca do aparato conceitual e descritivo desse campo de estudos, a fim de podermos pensar os âmbitos social e escolar, sobretudo ao tratar do processo de aprendizagem em leitura e escrita:

\begin{abstract}
Os estudos em cognição, sobretudo aqueles relacionados ao caráter processual da construção do significado, oferecem um arcabouço teórico-descritivo capaz de nos auxiliar a compreender os mecanismos, elementos e processos relacionados ao aprendizado, aqui visto como integração conceptual que conta com a articulação entre as bases de conhecimento existentes no "lado de dentro" e no "lado de fora", para que sejam criados novos conceitos, novas ideias. (GERHARDT, 2013, p.98).
\end{abstract}

A partir disso, é possível pensar que as atividades escolares, como a leitura e a escrita, precisam ser tratadas tanto sob um viés cognitivo-ecológico ${ }^{3}$ de significação do/com o mundo (DUQUE, 2018; GIBSON, 1979), quanto sob protocolos que auxiliem o aprendiz no gerenciamento dessas informações a significar ao ler e ao escrever, em termos da autorreflexão que constitui a base da consciência humana (METCALFE \& SHIMAMURA, 1994, p. xi).

Nossas ações cognitivas são passíveis de observação, análise e avaliação, sobretudo no que concerne aos processos de aprendizado escolar. A todo momento, monitoramos nossa postura social; organizamos nosso pensamento e nossos estudos, adequando-os aos nossos objetivos; reestruturamos nosso comportamento, de acordo com a exigência de cada ambiente etc. Este autoconhecimento, ou seja, essa administração que uma pessoa promove acerca de sua cognição é denominada metacognição. Essa habilidade está intimamente relacionada à

\footnotetext{
${ }^{3}$ Cognição ecológica - “corresponde à integração de estruturas conceptuais (frames) com a estrutura física do ambiente e as especificidades do corpo humano" (DUQUE, 2017, p. 23).
} 
capacidade de o sujeito administrar de seus próprios modos de pensar e das estratégias que pode empregar para resolver problemas, buscando identificar meios de aprimorar esse fazer (SCHWARTZ e PERFECT, 2002; TARRICONE, 2011, BOTELHO, 2015).

Em termos escolares, vale considerar que tais habilidades podem orientar as ações envolvidas em exercícios de leitura e de escrita, a fim de poder auxiliar os alunos na seleção de informações, com ações de autogerenciamento que favoreçam a construção de significados. Essas questões ressaltam a necessidade de nos debruçarmos sobre aparatos teóricos que configurem essas estratégias metacognitivas, como foi desenvolvido pelo quadro teórico de Nelson \& Narens (1990; 1994).

Como apontam estudos que têm pensado, sistematicamente, não apenas a constituição, mas também as estratégias para o aprimoramento da leitura e da escrita no espaço escolar junto aos aprendizes (GRIFFITH e RUAN, 2008; RANDI, GRIGORENKO e STERNBERG, 2008; VARGAS, 2012; NOBRE, 2012; ALMEIDA, 2017; PEREIRA, 2017), é possível atuar metacognitivamente por meio da proposta de questões orientadas sob objetivos e hipóteses flexíveis que auxiliem na compreensão e na construção de significados a partir da experiência com o texto. Assim, podemos dizer que o monitoramento e o controle são processos distintos que atuam articuladamente na construção de duas dimensões para a metacognição em atividades de leitura: (a) por um lado, o monitoramento pode corresponder, por exemplo, tanto às ações de autoavaliação que o aluno pode desenvolver por meio de previsões sobre seu desempenho na atividade de leitura ou de escrita, quanto às ações de julgamento sobre a própria atividade a ser realizada, a partir da formulação de hipóteses sobre um texto a ser lido; e (b) por outro lado, o controle da ação cognitiva pode corresponder às ações de gerenciamento propostas para que o aluno realize sua leitura, por exemplo, em função de um resultado desejado, a partir da postulação de objetivos e de estratégias para seleção de informações, da orientação das tarefas a serem realizadas e, possivelmente, da resolução de problemas.

\section{$2 \mathrm{Um}$ (re)pensar sobre as concepções de leitura}

A concepção de leitura apresentada nos livros didáticos disponíveis ao longo dos anos nas escolas brasileiras, como apontado por alguns estudos em leitura (BOTELHO, 2010; 2015; VARGAS, 2012; 2017), revela um direcionamento dos estudantes ao texto, pois será com base nele (apenas) que a leitura consistirá.

Essa concepção nos permite afirmar que, nesses espaços, a leitura tem se detido no nível inicial e mais superficial (APPLEGATE e cols., 2002; VARGAS, 2012), porque não tem sido explorada para promover a inte(g)ração entre texto e leitor (nos termos de VARGAS, 2017). Além disso, a organização das atividades de leitura, conforme essas concepções escolares, evidencia que os sujeitos não são considerados como estruturantes e necessários às significações envolvidas no processo de ler. Retomando alguns estudos que observam a leitura como atividade cognitiva e metacognitiva (KLEIMAN, 1995; FULGÊNCIO e LIBERATO, 1992; APPLEGATE e cols., 2002; VARGAS, 2012, entre outros), é possível apontar que essas concepções destoam do que se espera e do que se vem discutindo em termos da relação entre leitor e texto, pois não cabe mais pensar em ações leitoras que se detenham no texto como única e exclusiva fonte de informações e de possibilidades de significação.

Tais evidências nos mostram que pensar a formação escolar requer outras ações leitoras para além do que se tem desenvolvido - o modelo de reprodução de informações. Desenvolver a leitura requer, também, aprender a estabelecer e a gerenciar relações inferenciais, por meio das quais se dará a significação a partir do que se leu, e a construir uma leitura global que fundamente o desenvolvimento de um olhar mais crítico acerca do material lido (APPLEGATE e cols., 2002; VARGAS, 2017; NOBRE, 2019). Sendo assim, perceber, conforme os estudos aqui já apontados, a ampla oferta de atividades sob o modelo de reprodução de informações em materiais didáticos 
de Língua Portuguesa nos conduz a pensar nas questões que se impõem em termos da formação leitora nas escolas brasileiras, tendo em vista que há um problema metodológico na organização das atividades ofertadas, que não contemplam os saberes dos estudantes como estruturantes e não os consideram agentes do processo de ler (GERHARDT, 2013).

Considerando a realidade escolar, atividades desenvolvidas sob esse modelo acabam por construir nos estudantes a falsa visão de que são incapazes de ler de forma agentiva e criativa, pois o texto acaba tornando-se meio e fim, não somente nos livros didáticos presentes no espaço escolar, mas, sobretudo, fora da escola. Pensando sob essa ótica, é bastante comum perceber, entre os estudantes, um comportamento mecanizado e nada prazeroso com a leitura, pois muitos associam esse tipo de atividade a tarefas de compreensão por meio de reprodução de informações, o que termina por construir uma visão de leitura estanque e fundada nesse modelo decodificador, direcionada a qualquer material e, também, às futuras avaliações propostas na escola.

Além disso, reconhecer que há uma concepção equivocada sobre o que é ler e perceber que, ao longo dos anos, essas práticas reprodutoras se replicam, permitem-nos perceber a necessidade de propor um olhar sobre a atividade de leitura que mostre aos estudantes formas de explorar suas potencialidades como leitores.

Para este estudo, a compreensão do que abrangem as atividades de leitura e de escrita em sala de aula remonta a Vargas (2017), que apontou a necessidade de construir "políticas inventivas". A partir dessa premissa, a metacognição, sob a visão do pesquisador, despontaria como suporte para fundamentar algumas questões: de atenção às características do texto a ser lido/produzido, de regulação de ações relevantes às tarefas, de seletividade de informações, de instruções a serem seguidas.

Além disso, os estudos em metacognição fornecem um importante suporte para pensar comandos e estabelecer práticas voltadas tanto aos objetivos de realização, quanto ao gerenciamento de ações que permitam o desenvolvimento eficaz dos processos de ler e de escrever. Pensar atividades de leitura e de escrita por meio do gerenciamento de ações em cada etapa a realizar nessas tarefas, como, por exemplo, em cada comando de questões e sugestões de protocolos, é um caminho para que os aprendizes, pouco a pouco, possam pensar sobre o que se torna possível construir no e com o texto.

Para Vargas (2017), a reflexão sobre inferências construídas ou as que se poderiam construir é uma ação necessária para a melhoria da integração entre alunos e textos. Sendo assim, seria possível ao aprendiz o reconhecimento tanto do direcionamento dado às suas ações - para ler e para escrever - como também o gerenciamento das fontes de informação e do que se pretende significar por meio da relação com o texto. Pensar sobre as informações localizadas no texto e reconhecer os saberes presentes no conhecimento prévio dos aprendizes já são, necessariamente, ações metacognitivas relevantes para a realização dessas atividades.

\section{0 conceito de letramento linguístico e as práticas em leitura e escrita}

Consideramos fundamental observar e analisar as práticas de leitura e escrita nos diferentes contextos em que ocorrem, de modo que se possa descrever os processos e ações (meta)cognitivas das pessoas, nesses contextos, ao interagir por meio da linguagem - com especial atenção ao gerenciamento dos aspectos referentes à língua/linguagem. Como fundamento teórico para esse direcionamento, recorremos ao conceito de letramento linguístico de Ravid e Tolchinsky (2002), que consiste no domínio progressivo sobre as múltiplas possibilidades de uso da língua, nas dimensões do registro, do gênero e da modalidade; quanto à modalidade escrita, esse domínio compreende perceber a escrita como estilo discursivo e como sistema notacional. Sendo este a organização dos sinais gráficos que compõem os textos, interessa-nos aqui comentar aquele, que se define como o conhecimento dos 
usos sociais da língua, por meio de gêneros textuais. O diferencial, de fato, na proposta das autoras é o papel da consciência metalinguística no desenvolvimento do letramento. Essa consciência se define como o campo da metacognição que se refere ao conhecimento, às práticas e reflexões com e sobre a língua (GOMBERT, 1992). Tal conceito será retomado na seção 4; por ora, é suficiente apontar que, na visão de Ravid e Tolchinsky, é componente intrínseco ao desenvolvimento do letramento o igual desenvolvimento da capacidade de autogerenciar os conhecimentos e usos da linguagem.

Uma vez que, para as autoras, a categoria dos gêneros textuais compõe a perspectiva de uso da língua escrita como estilo discursivo, percebemos como imperativo o trabalho com os gêneros também direcionado para a observação dos processos individuais que atuam nessa construção de textos forjados nos usos cotidianos e sociais, e também balizadores desses usos (GERHARDT, 2015). Pensar a (meta) cognição, neste caso, ao contrário de restringir a atenção ao campo do indivíduo, como se pode pensar, permite um alcance maior da atuação dessa pessoa, uma vez que se pretende desnaturalizar práticas e conhecimentos sobre a leitura e a escrita de textos em gêneros diversos, a fim de ensinar a escrever com mais agenciamento (LESSA, 2013).

\section{Da leitura para a escrita - algumas propostas de revisão}

A reflexão sobre como o ensino da leitura se concretiza na escola e nos materiais didáticos estende-se para a reflexão sobre o ensino da escrita e sua sistematização no mesmo contexto. Quanto a trabalhos pioneiros nessa área no Brasil, podemos nos remeter a Pécora (2002 [1983]), Geraldi (2006 [1984]) e Val (1999 [1991]), para citar apenas três, que analisaram redações de vestibular, sistematizaram e debateram problemas de ordem semântica, sintática e discursiva. Mesmo levando em consideração a relevância desses trabalhos, optamos por nos concentrar naqueles que problematizam não o produto da escrita, o texto pronto, mas o processo, aspecto em geral ainda negligenciado em materiais didáticos contemporâneos. Afinal, parece faltar uma orientação clara ao aluno para a processualidade das diversas tarefas envolvidas na habilidade de produzir textos escritos (PEREIRA, 2017; ALMEIDA, 2017).

Almeida (2017) aborda a dificuldade que os estudantes apresentam de organizar as informações estruturando parágrafos adequados. Privilegiando a orientação para os procedimentos de ordem cognitiva e metacognitiva, o autor propõe uma abordagem didática que contempla tais habilidades. Já Pereira (2017) destaca a lacuna no ensino da revisão e da reescrita do texto, conclusão a que chega após a análise de seis coleções de livros didáticos de língua portuguesa para o ensino fundamental aprovadas pelo PNLD 2017. A autora também propõe a didatização desses processos no ensino de língua materna e apresenta uma proposta teóricodidática fundamentada no gerenciamento metalinguístico.

Outro caminho para pensarmos a possibilidade de fundamentar (meta)cognitivamente o ensino da escrita na escola é observar a dinâmica de produção de um gênero textual bastante comum em diversas disciplinas: o par pergunta-resposta discursiva. Desde as primeiras séries do ensino fundamental, os alunos precisam responder a questões que se fundamentam em um texto, tanto na disciplina língua portuguesa quanto em outras, como história, geografia, sociologia, biologia. Se, como já comentado na seção 1, o que se espera dessa leitura, na escola, muitas vezes é apenas o nível mais superficial de compreensão, por meio da extração de dados do texto, também as respostas dadas pelos alunos em questões discursivas de avaliações não vão muito além, mesmo que as perguntas exijam maior grau de inferenciação - e é aí que reside o problema.

Acostumados a uma prática de relação com os conteúdos escolares que os configura como blocos de informação a serem armazenados, os alunos desenvolvem estratégias do que chamaremos aqui de cognição definicional (NEVES, 2015): passam a olhar para as aulas, os textos e os conteúdos em busca apenas de conceitos, definições, enunciados que possam ser 
extraídos, aprendidos (em geral, decorados) e usados como respostas às questões. Ainda que a construção de respostas para essas perguntas requeira práticas de cognição relacional (GENTNER e LOEWESTEIN, 2002; NEVES, 2015) - comparação entre conceitos para produção de conclusões, confrontação entre conceitos e fenômenos, descrição e análise, por exemplo - os estudantes tendem a não reconhecer nem validar esses comandos nas questões, nem os raciocínios a eles relacionados. Esses problemas não deixam de ser também um sintoma da percepção (muitas vezes ensinada no contexto escolar) do texto como produto, já que o que parece valer é apenas o preenchimento do espaço de resposta com as informações relacionadas aos conteúdos em estudo, (supostamente) exigidas pelos professores, e não a construção de uma trajetória argumentativa fundamentada em conceitos estudados.

Nesse sentido, a proposta que trazemos para o ensino da escrita implica pensá-la não apenas como forma de registrar e memorizar conteúdos, mas, conforme sintetiza Newell (2006, p. 235), como caminho para a aprendizagem e criação de novas ideias; como oportunidade de contato com diferentes convenções e gêneros, em diferentes contextos; como reconfiguração dos papéis do professor - de avaliador para colaborador - e do estudante - de memorizador para construtor de significado. Implica também problematizar a atitude da pessoa que escreve diante da sua atuação como produtor de textos: o envolvimento se dá apenas por obrigação, ou há um comprometimento pessoal com a escrita (BRITTON e cols., 1975)? Foram estabelecidos objetivos claros e exequíveis? Em outras palavras, que consciência tem o aluno das estratégias metacognitivas/metalinguísticas que empreende para produzir um texto? Que fique claro: para que o estudante possa "mudar de atitude" diante da tarefa de escrever, é preciso, primeiro, que a escola e o professor promovam uma reconfiguração do espaço de ensino-aprendizagem, de modo a acolher as demandas dos alunos e favorecer a atenção aos aspectos metacognitivos da escrita.

Em termos conceituais, pensar a escrita em uma perspectiva (meta)cognitiva pressupõe considerar a processualidade da atividade e das diversas tarefas envolvidas, situadas em diferentes contextos, sobretudo os de ensino-aprendizagem institucionalizado (SINHA, 1999). Ainda que dentro do espaço escolar, escrever não se configura da mesma forma nas diversas disciplinas (BRITTON e cols., 1975). Mais do que as diferenças próprias dos gêneros textuais resumos de texto literário, resumos de texto de História, relatório de experimento em Química importa aqui a compreensão do próprio produtor de textos, estudante, sobre as funções da sua escrita naquele contexto e as ações que executará para atendê-las. Em primeiro plano, estão a escolha e o gerenciamento das próprias estratégias relacionadas à linguagem - a atividade metalinguística (GOMBERT, 1992), já introduzida na seção 3.

O desenvolvimento metalinguístico, conforme sistematizado por Gombert (1992, p. 13), refere-se a um campo da metacognição que envolve tanto a reflexão sobre a linguagem e seus usos quanto a habilidade de monitorar e planejar, de forma consciente, as próprias estratégias de processamento linguístico. Esses procedimentos incidem sobre os diversos aspectos da linguagem: fonológico, sintático, semântico, pragmático e textual, o qual será aqui privilegiado. Trata-se do gerenciamento metatextual, que, para o autor, abarca o monitoramento da coerência (aspecto semântico), da coesão (morfossintático) e da estrutura do texto. Expandiremos a compreensão e a aplicação do primeiro e do terceiro aspectos, por razões que ficarão mais claras no decorrer da exposição.

O gerenciamento metalinguístico da coerência de um texto se manifesta, segundo o autor: a) no confronto entre informações novas presentes no texto e o conhecimento prévio da pessoa envolvida; b) no monitoramento da coerência intratextual (compatibilidade entre as ideias expressas em diferentes partes do texto); c) no monitoramento das inferências. Já o gerenciamento da estrutura, para os fins deste artigo, envolve a identificação do tema do texto e a percepção da hierarquia de importância dos argumentos. 
Ressaltamos que esse gerenciamento, embora à primeira vista pareça referir-se apenas à leitura, também se aplica diretamente à produção escrita: no processo de elaborar, revisar e reescrever seu texto, quanto ao gerenciamento da coerência, o estudante precisa: a) avaliar se consegue explicitar as relações entre os conhecimentos prévios necessários para que o leitor compreenda o texto e as ideias ali expostas; b) detectar e monitorar as relações entre os argumentos apresentados em diferentes partes do texto, começando essa tarefa pelo planejamento textual; c) procurar prever inferências que possam ser feitas pelo leitor a partir dos recursos linguísticos empregados e das possibilidades de ativação de conhecimento prévio que seu texto suscita, para tentar evitar significados contraditórios com os que pretende construir. Quanto ao gerenciamento da estrutura, o produtor de textos precisa monitorar o grau de explicitação tanto do tema, por meio do título, da estruturação dos parágrafos e de outros recursos, quanto da hierarquia dos argumentos, selecionando estratégias e recursos linguísticos (como conectores) capazes de pôr em perspectiva ideias centrais e secundárias.

Assim, a fim de contribuir com o gerenciamento metalinguístico conforme detalhado até aqui, trazemos a proposta das ações com a escrita (NEVES, 2015; 2016), que, de forma esquemática, contribui para que o aluno empreenda os procedimentos metalinguísticos sugeridos por Gombert (1992).

A proposta de gerenciamento das ações com a escrita foi pensada e desenvolvida para o trabalho com gêneros textuais acadêmicos. Porém, também se aplica a gêneros que sirvam para a educação básica, especialmente aqueles que sejam predominantemente argumentativos e dialógicos. A principal finalidade do olhar para as ações no texto e para sua administração em todo o processo de leitura-escrita é hierarquizar a percepção do leitor acerca do papel e da relevância dos enunciados. Acreditamos que esse processo torna mais focadas e produtivas a leitura - entendida como seleção e gerenciamento de informações - a aprendizagem de conteúdos e, posteriormente, a escrita que derivará do material lido, ou se fundamentará nele.

$\mathrm{Na}$ perspectiva metacognitiva e metalinguística da leitura-escrita, ou seja, a administração da própria cognição pelo leitor-produtor de textos, as ações com a escrita dizem respeito também à detecção dos objetivos estabelecidos pelo autor ao escolher de que modo selecionar e estruturar as informações em diferentes níveis de relevância; da mesma forma, mas em sentido inverso, a consideração dessas ações se presta à estruturação do próprio texto acadêmico (ou de outro domínio, mas de base argumentativa) pelo estudante/aprendiz. A percepção e a apropriação dessas ações cognitivas pelo estudante, na leitura e na produção do texto acadêmico, consistem naquilo que consideramos o diferencial no desenvolvimento do letramento linguístico acadêmico (NEVES, 2016): para além do conhecimento sobre os gêneros textuais próprios do discurso acadêmico (tópico já mencionado na seção 3) e das características mais amplas da interlocução nesse âmbito (saber fundamental para circular em tal contexto), a proposta das ações com a escrita permite que o estudante se observe, identifique e considere como pessoa integrante de tal interlocução, capaz de compreender, produzir e gerenciar a linguagem empregada para efetuar as ações nos textos.

As ações com a escrita que delimitamos são as de reportar, sumarizar, analisar e teorizar (NEWELL, 2006; NEVES, 2015, 2016). Com a ação de reportar, o autor de um artigo acadêmico, por exemplo, refere-se a dados, informações, acontecimentos e textos, a fim de expor, descrever ou narrar fatos e fenômenos seletivamente, ou seja, direcionando o olhar do leitor a aspectos específicos que sirvam de fundamento para a argumentação desenvolvida. $\mathrm{Na}$ ação de sumarizar, o autor guia o leitor ao longo do texto, a partir de sinalizações (por meio de recursos linguísticos) que podem incidir tanto sobre a estrutura do gênero - por exemplo, indicação do objetivo, da hipótese ou dos resultados - quanto sobre o conteúdo temático. Neste caso, a sumarização pode se revelar em sequências ou cadeias referenciais (ALMEIDA, 2010), que estruturam o conteúdo em ordenações como geral-específico/específico-geral, ou causaconsequência, por exemplo (NEVES, 2016, p. 479). 
Com a ação de analisar, o autor explicita as relações lógicas, semânticas e discursivas entre fenômenos (fatos, situações) e proposições (conceitos, princípios), ao interpretar tais fenômenos à luz dos posicionamentos teóricos reportados e sumarizados no texto e ao explicitar textualmente essa interpretação (NEVES, 2016, p. 480). Por fim, na ação de teorizar, o autor consolida seu posicionamento e de seu grupo na comunidade científico-acadêmica por meio da proposição de conceitos e generalizações sobre o tema. Tais formulações costumam se apresentar em forma de enunciados categóricos que carregam a marca da autoria, já que são produto de processo analítico e posicionamento crítico-ideológico, fundamentado em outras leituras e estudos. A ação de teorizar é bastante típica de gêneros acadêmicos e costuma ser a de maior importância (NEVES, 2016, p. 480).

A possibilidade de observar e gerenciar tais ações tanto na leitura quanto na escrita ratifica a escolha por uma abordagem processual das duas atividades, já que a construção de uma hierarquia de informações em um texto requer: a) inicialmente, a percepção dessa hierarquia em textos de gêneros acadêmicos (ou de base argumentativa), como elemento estruturante desses gêneros; b) a progressiva construção da ordenação informacional no ato de conceber e planejar uma resposta a uma questão discursiva, por exemplo, tendo como norte objetivos bem definidos (a partir do enunciado da questão); c) a elaboração de períodos e parágrafos que explicitem cada ação para o leitor, de forma a guiá-lo na percepção da hierarquia textual. Dessa forma, pretendemos oferecer ao estudante uma orientação sistemática para a resposta a questões discursivas, o que, salvo exceção, não costuma ser feito com essa especificidade no ensino fundamental e médio.

\section{Leitura e escrita: apontando caminhos, pensando o ensino e propondo estratégias}

As reflexões já apontadas acerca das concepções leitoras no espaço escolar revelam que não pensar as atividades escolares tendo os saberes dos estudantes como ponto de partida e não propor objetivos claros para realizar essas atividades advém de uma cognição escolar que não enxerga a pertinência daquilo que alunos trazem consigo. Assim, mantém-se uma perspectiva de construção das atividades sob um modelo de ensino com enfoque conteudista acerca das informações que, em tese, esses estudantes desconhecem.

Essa forma de pensar a atividade escolar não considera os conhecimentos prévios desses alunos como componente das etapas que serão relevantes à significação e ao aprendizado. Cabe apontar, também, que tais ações não permitem estabelecer entre os aprendizes problematizações acerca do caráter processual e, portanto, singular da relação que se estabelece entre aprendiz e texto - para ler e para escrever. É relevante, por isso, propor a definição de leitura como uma ação que se constitui por meio da relação entre os conhecimentos do leitor e as informações trazidas pelo texto, tendo em vista a construção de uma leitura em que o aluno se reconheça como parte do processo, a fim de propiciar a melhoria de qualidade no seu desenvolvimento na escola. Para que tal ação possa acontecer com qualidade no espaço escolar, é importante que seu desenvolvimento esteja atrelado a algumas estratégias metacognitivas, como, por exemplo, a proposta de questões que auxiliem no acionamento do conhecimento prévio do leitor, com seleção de informações que serão pertinentes ao que será trabalhado na atividade e, também, o estabelecimento de objetivos para cada etapa da atividade de leitura.

Nesse sentido, pensando as atividades de leitura, Botelho (2015) propõe uma revisão do modelo proposto por Nelson e Narens (1994), como exposto:

(i) As tarefas do estágio de aquisição incluem o recrutamento de dados do objeto de estudo para a checagem das estratégias utilizadas - no caso, o enquadramento, na memória rasa, de conhecimentos prévios que são importantes para uma boa leitura do texto. 
(ii) No estágio de retenção, administra-se a coleta e a manutenção do aprendizado do objeto de estudo, em relação aos conhecimentos prévios levantados e aos objetivos de leitura.

(iii) O estágio final de recuperação contém atividades de fixação e verificação da aprendizagem e de checagem do alcance dos objetivos de leitura. Nesse estágio, é possível refletir sobre a relação entre os dados recrutados e os conhecimentos prévios dos alunos, em vias de validar as informações capturadas durante a leitura (BOTELHO, 2015, p. 42,43).

A atividade de leitura envolve uma estreita relação social e política, considerando que está intimamente relacionada à formação cidadã dos estudantes e às políticas cognitivas que se processam no espaço escolar. Sobre isso, Vargas (2017) aponta estratégias que concebem a leitura como uma inte(g)ração de saberes, até pela necessidade de assumir que a construção dos significados em leitura envolve o processo inferencial. O autor também aponta a importância de promover práticas escolares inventivas, não mais reprodutoras, tendo em vista o aspecto processual da leitura, que envolveria considerá-la sob o viés criativo. Sendo assim, Vargas, ao postular que as ações leitoras são instanciadas pela inferenciação, indica as seguintes questões como fundamentos, a fim de pensar os alunos como sujeitos da sua aprendizagem:

a) sejam elaboradas questões de pré-leitura, que solicitem a ativação de conhecimentos prévios do leitor ou o auxiliem na construção de conhecimentos necessários para o desenvolvimento de sua leitura e que contribuam - ou ofereçam provisoriamente para o estabelecimento de objetivos de leitura;

b) questões de leitura, que possam auxiliar o aluno em seu processo de integração com o que lê, através de questões que priorizem os níveis mais inferenciais de leitura, usando o nível literal apenas como suporte para a construção de inferências; e

c) questões de pós-leitura, que busquem o desenvolvimento de reflexões a partir da articulação entre o que o leitor sabia antes e o que ele aprendeu ao longo de sua leitura. (VARGAS, 2017, p. 203)

A partir dessas questões, o autor aponta que, por ser a inferenciação processo básico de construção de conhecimentos em leitura, é por meio dela que se dá a integração entre texto e conhecimentos prévios do leitor. Para tanto, torna-se relevante compreender esses processos inferenciais a fim de pensar a seletividade das informações esperadas nas atividades. Se a atividade de leitura não propuser uma organização que auxilie o estudante a pensar sobre o que realiza enquanto lê, por vezes, os processos inferenciais não corresponderão à leitura prevista pela atividade, como bem apontado por Vargas (2017). De acordo com o pesquisador, em algumas questões de leitura propostas em livros didáticos, a imprevisibilidade das respostas dos estudantes (as quais, muitas vezes, destoam da proposta de gabarito desses materiais) deriva, justamente, da base que o aluno-leitor usará na seleção dos dados do texto.

Uma vez mais, pensando nas discussões aqui propostas, as estratégias metacognitivas serão relevantes na organização das atividades, tanto para instanciar a seleção de conhecimentos prévios no estágio de pré-leitura, a fim de ambientar o estudante com o que será explorado nas atividades, quanto, também, para pensar a seletividade da informação requerida para a construção das inferências pretendidas na leitura proposta. Vale dizer que, em termos metacognitivos, quando o aluno considera que ler é reproduzir informações e, assim, não aprende a desconfiar do texto que produz e a reconhecer o que é exigido nas atividades propostas, pode correr o risco de selecionar informações, inclusive, oriundas apenas do conhecimento prévio, que não fazem parte do que consta no texto.

A proposta que traçamos aqui, tanto para a leitura como para a escrita, atravessa, em certa medida, a discussão de Nobre (2019) sobre o gerenciamento das informações para a formação de um leitor crítico, que aponta para a importância de tratar o aprendizado dessas habilidades tendo em perspectiva a necessidade de negociação de informações processadas pelo 
aprendiz. Para a autora, há, no caminho da seleção de conhecimento prévio e das informações do texto para o desenvolvimento dessas atividades, formas de gerenciar, via atividades escolares, um olhar que desconfie da própria leitura/escrita, como forma de pensar criticamente o aprendizado.

Em síntese, saber que o aluno é capaz de pensar processualmente enquanto realiza suas tarefas e que o desenvolvimento de um pensar sobre seu próprio pensar pode ser aprendido são premissas fundamentais na trilha do ensino de leitura no ambiente escolar. Nesse sentido, as estratégias metacognitivas são, aqui, um meio para que os alunos possam reconhecer o que conseguem e o que não conseguem compreender acerca das atividades que desenvolvem. Os caminhos apontados pelos estudos já citados acerca das estratégias e formas de (re)pensar as concepções de leitura só poderão, a nosso ver, ser eficientemente promovidos a partir da criação de espaços e/ou de atividades que possibilitem aos alunos refletir, minimamente, e se perceberem agentes de seus conhecimentos.

\section{CONSIDERAÇÕES FINAIS}

Este artigo propôs-se a apresentar orientações teórico-descritivas sobre as concepções de leitura e de escrita, partindo, para isso, de alguns diagnósticos já apontados em pesquisas que nortearam as premissas deste estudo. Tendo em vista as concepções de leitura e escrita no espaço escolar, pudemos, então, propor a revisão desses conceitos sob um viés processual e, assim, (re)pensar essas atividades fundamentadas nos estudos em metacognição e em gerenciamento metalinguístico.

Por meio das questões propostas, pudemos chegar a algumas afirmações interessantes acerca das atividades de leitura e escrita, que merecem destaque:

1) Em termos das concepções de leitura, o modelo de reprodução de conteúdos e a naturalização de práticas limitadoras nos estudantes apontaram a necessidade de mostrar a eles formas de explorar suas potencialidades como leitores, pois reconhecemos que não cabe mais propor leituras que se detenham no texto como fonte preponderante de informações e de possibilidades de significação.

2) Em termos das concepções de escrita, apontamos que ainda há uma negligência dos materiais didáticos contemporâneos ao tratarem-na como produto e não como processo e, também, ao deixarem de apontar orientações claras ao aluno para a processualidade das diversas tarefas envolvidas na habilidade de produzir textos escritos.

3) Neste estudo, destacamos que o aluno precisa se reconhecer como parte do processo de ler, para pensar, nesse sentido, a melhoria de qualidade no seu desenvolvimento na escola. Em auxílio a isso, sugerimos: (i) ações de gerenciamento metacognitivo como forma de potencializar as capacidades dos alunos nos seus processos de significação e (ii) a definição de leitura como uma ação que se constitui por meio da relação entre os conhecimentos do leitor e as informações trazidas pelo texto.

4) A proposta que trazemos, neste estudo, para o ensino da escrita aponta um caminho para além de ações de registro de informações. A escrita precisa ser planejada e executada com base em objetivos claros que propiciem a aprendizagem e a criação de novas ideias e que apontem formas de lidar com diferentes convenções linguísticas e gêneros, em diferentes contextos e práticas sociais.

Vale apontar que as estratégias metacognitivas são um caminho de orientação sobre as formas como as pessoas podem gerenciar suas atividades e, em termos do ensino de leitura e de escrita, estão relacionadas à importância de pôr em perspectiva a necessidade de negociação de informações focada no aprendizado. O ensino de leitura e escrita requer que se priorize, como buscamos apontar, via atividades escolares, o gerenciamento de ações, estratégias que auxiliem na seleção das informações envolvidas no processo de ler e de escrever e, também, um 
posicionamento desconfiado sobre a própria leitura e a escrita, a fim de não deixar de pensar criticamente o aprendizado.

\section{REFERÊNCIAS BIBLIOGRÁFICAS}

ABREU, Cybelle Borges de. A incompletude gramatical: articulação entre os ensinos de gramática e de escrita. 2017. Dissertação (Mestrado em Letras Vernáculas) - Faculdade de Letras, Universidade Federal do Rio de Janeiro, Rio de Janeiro, 2017.

ALMEIDA, Marcus V. B. Polissemia e progressão referencial em redações de vestibular. 2010. Dissertação (Mestrado em Letras Vernáculas) - Faculdade de Letras, Universidade Federal do Rio de Janeiro, Rio de Janeiro, 2010.

ALMEIDA, Marcus V. B. O redator estrategista: uma proposta metacognitiva para o ensino da organização tópica do parágrafo argumentativo. 2017. Tese (Doutorado em Letras Vernáculas) Faculdade de Letras, Universidade Federal do Rio de Janeiro, Rio de Janeiro, 2017.

APPLEGATE, Mary DeKonty, QUINN, Kathleen Benson, APPLEGATE, Anthony. J. Levels of thinking required by comprehension questions in informal reading inventories. The Reading Teacher, 56 (2): 174-180, 2002.

BOTELHO, Patricia Ferreira. Textos factuais e problematizantes em livros didáticos de História: leitura e metacognição. 2010. Dissertação (Mestrado em Letras Vernáculas) Faculdade de Letras, Universidade Federal do Rio de Janeiro, Rio de Janeiro, 2010.

BOTELHO, Patricia Ferreira. Conhecimento prévio e atividades escolares de leitura - uma abordagem cognitiva e metacognitiva. 2015. Tese (Doutorado em Letras Vernáculas) - Faculdade de Letras, Universidade Federal do Rio de Janeiro, Rio de Janeiro, 2015.

BRITTON, James e cols. The development of writing abilities (11-18). Londres: Macmillan Education, 1975.

DUQUE, Paulo Henrique. De perceptos a frames: cognição ecológica e linguagem. Scripta, Belo Horizonte, v. 21, n. 41, p. 21-45, $1^{\circ}$ sem. 2017.

DUQUE, Paulo Henrique. Percepção, linguagem e construção de sentidos: por uma abordagem ecológica da cognição. In: Uma abordagem cognitiva da linguagem [livro eletrônico]: perspectivas teóricas e descritivas / organizadoras: Adriana Maria Tenuta, Sueli Maria Coelho. Belo Horizonte: FALE/UFMG, 2018.

FULGÊNCIO, Lúcia.; LIBERATO, Yara. Como facilitar a leitura. São Paulo: Contexto, 1992.

GENTNER, Dedre; LOEWENSTEIN, Jeffrey. Relational language and relational thought. In: AMSEL, Eric.; BYRNES, James P. Language, literacy and cognitive development. New Jersey: Lawrence Erlbaum Associates, 2002.

GERHARDT, Ana Flávia Lopes Magela. As identidades situadas, os documentos curriculares e os caminhos abertos para o ensino de língua portuguesa no Brasil. In: GERHARDT, Ana Flávia Lopes Magela; AMORIM, Marcel Alvaro; CARVALHO, Alvaro M. (orgs.). Linguística aplicada e ensino: língua e literatura. Campinas, SP: Pontes Editores, 2013, p. 77-113. 
GERHARDT, Ana Flávia Lopes Magela. O conhecimento metalinguístico, os enquadramentos da construção dos significados nos textos e o ensino de língua portuguesa. Alfa: Revista de Linguística (UNESP. Online), v. 59, p. 231-254, 2015.

GERALDI, João Wanderley. O texto na sala de aula. 4. ed. São Paulo: Ática, 2006 [1984].

GIBSON, James. J. The ecological approach to visual perception. 1. ed. Boston: Houghton Mifflin, 1979.

GOMBERT, Jean Émile. Metalinguistic development. Chicago: The University of Chicago Press, 1992.

GRIFFITH, Priscilla. L.; RUAN, Jiening. What Is Metacognition and What Should Be Its Role in Literacy Instruction? In: ISRAEL, S; BLOCK, C; BAUSERMAN, K; KINUCAN-WELSH, K. (Eds.). Metacognition in literacy learning. London: Lawrence Erlbaum, 2008. p. 03-19.

KLEIMAN, Ângela. Texto e leitor: aspectos cognitivos da leitura. Campinas: Pontes, 1995.

LESSA, Paula Regina de Andrade. A articulação de orações na Oficina de Língua Portuguesa (CLAC/UFRJ) e o saber do aluno na produção textual. 2013. Dissertação (Mestrado em Letras Vernáculas) - Faculdade de Letras, Universidade Federal do Rio de Janeiro, Rio de Janeiro, 2013.

NELSON, T. O.; NARENS, L. Why investigate metacognition. In: METCALFE, J.; SHIMAMURA, A. P. (eds.). Metacognition - knowing about knowing. Cambridge, Massachusetts: The MIT Press, 1994.

NEVES, Fabiana Esteves. Letramento linguístico acadêmico de estudantes universitárias/os: gerenciamento metalinguístico na leitura e na escrita. 2015. Tese (Doutorado em Letras Vernáculas) - Faculdade de Letras, Universidade Federal do Rio de Janeiro, Rio de Janeiro, 2015.

NEVES, Fabiana Esteves. Conhecimento metalinguístico em uma perspectiva (meta)cognitiva letramento linguístico acadêmico da/o estudante universitária/o. Revista do Programa de PósGraduação em Letras da Universidade de Passo Fundo, v. 12, n. 2, p. 473-495, jul./dez. 2016.

NEWELL, George E. Writing to Learn. How alternative theories of school writing account for student performance. In: MACARTTHUR, Charles A.; GRAHAM, Steve; FITZGERALD, Jill. Handbook of writing research. Nova York: The Guilford Press, 2006.

NOBRE, Natalia de Lima. O processamento discursivo e suas bases corpóreas: estratégias cognitivas de alunos da educação de jovens e adultos na compreensão de narrativas. 2012 Dissertação (Mestrado em Linguística) - Centro de Ciências Humanas, Letras e Artes, Programa de Pós-Graduação em Estudos da Linguagem, Universidade Federal do Rio Grande do Norte, Natal, 2012.

NOBRE, Natalia de Lima. Uma proposta metacognitivista de trabalho de Letramento Crítico no Ensino Superior: a contribuição dos conceitos de frame e reframing. Rio de Janeiro, 
2019. Tese (Doutorado Interdisciplinar em Linguística Aplicada). Faculdade de letras, Universidade Federal do Rio de Janeiro, Rio de Janeiro, 2019.

PÉCORA, Alcir. Problemas de redação. 5. ed. 3. tir. São Paulo: Martins Fontes, 2002 [1983].

PEREIRA, Luciana Faria. Produção de texto e desenvolvimento metalinguístico: por uma reescrita como escrita. 2017. Dissertação (Mestrado em Letras Vernáculas) - Faculdade de Letras, Universidade Federal do Rio de Janeiro, Rio de Janeiro, 2017.

RANDI, Judi.; GRIKORENKO, Elena L.; STERNBERG, Robert J. Revisiting definitions of reading comprehension: Just what is reading comprehension anyway? In: ISRAEL, Susan E.; BLOCK, Cathy C.; BAUSERMAN, Kathryn L.; KINUCAN-WELSH, Kathryn. (Eds.). Metacognition in literacy learning. London: Lawrence Erlbaum, 2008.

RAVID, Dorit.; TOLCHINSKY, Liliana. Developing linguistic literacy: a comprehensive model. Journal of Child Language, 29, p. 417-447, 2002.

SINHA, Christopher. Situated selves: learning to be a learner. In: BLISS, J.; SÃLJÕ, R. e LIGHT, P. (Eds.). Learning sites: social and technological resources for learning (pp. 32-48). Oxford: Pergamon, 1999.

TARRICONE, Pina. The taxonomy of metacognition. Hove: Psychology Press, 2011.

VAL, Maria da Graça Costa. Redação e textualidade. $2^{a}$ ed. São Paulo: Martins Fontes, 1999 [1991]. (Coleção Texto e Linguagem).

VARGAS, Diego da Silva. O plano inferencial em atividades de leitura: livro didático, cognição e ensino. 2012. Dissertação (Mestrado em Letras Vernáculas) - Faculdade de Letras, Universidade Federal do Rio de Janeiro, Rio de Janeiro, 2012.

VARGAS, Diego da. Silva. O plano inferencial da leitura e o ensino de espanhol na escola brasileira: cognição distribuída, políticas cognitivas e livro didático. 2017. Tese (Doutorado em Programa de Pós-graduação em Letras Neolatinas), Faculdade de letras, Universidade Federal do Rio de Janeiro, Rio de Janeiro, 2017.

Submetido em $01 / 12 / 2018$

Aceito em 26/08/2019

Publicado em 30/08/2019 